\title{
The Effects of 2-year Treatment with the Aminobisphosphonate Alendronate on Bone Metabolism, Bone Histomorphometry, and Bone Strength in Ovariectomized Nonhuman Primates
}

\author{
R. Balena, ${ }^{1}$ B. C. Toolan, ${ }^{1}{ }^{*}$ M. Shea, ${ }^{*}$ A. Markatos, E. R. Myers, ${ }^{\star}$ S. C. Lee, ${ }^{\star}$ E. E. Opas, J. G. Seedor, H. Klein, \\ D. Frankenfield, H. Quartuccio, C. Fioravanti, J. Clair, E. Brown, W. C. Hayes, * and G. A. Rodan \\ Merck Research Laboratories, West Point, Pennsylvania 19486; and * Beth Israel Hospital, Boston, Massachusetts 02215
}

\begin{abstract}
This study examined the effect of $2 \mathrm{yr}$ of treatment with the aminobisphosphonate alendronate (ALN) (0.05 or $0.25 \mathrm{mg} /$ kg i.v. ALN every 2 wk) on estrogen deficiency bone loss and bone strength changes in ovariectomized (OVX) baboons ( $n$ $=7$ per group) and the ALN mode of action at the tissue level. Biochemical markers of bone turnover increased in OVX animals and were maintained by ALN treatment at non-OVX levels (low dose) or below ( high dose). 2 yr of treatment produced no cumulative effects on bone turnover markers. Histomorphometry showed a marked increase in cancellous bone remodeling in OVX animals. Activation frequency increased from 0.48 to 0.86 per yr (L5 vertebra), and the osteoid surfaces from 9 to $13.5 \%(P<0.05)$. No changes were observed in eroded and osteoclast surfaces. ALN treatment decreased activation frequency and indices of bone formation to control levels (low dose) or below (high dose), did not change indices of mineralization, and increased bone mineral density (BMD) in the lumbar vertebrae $(\mathrm{L} 2-\mathrm{LA})$ by $15 \%$ at $0.25 \mathrm{mg} / \mathrm{kg}(P<0.05)$, relative to vehicle-treated animals. The mean strength of cancellous bone ( $L 4$ ) increased by $44 \%$ (low ALN dose) and $100 \%$ (high dose), compared with vehicle. The strength of individual bones correlated with the square of the L2-LA BMD $(r=0.91$, $P<0.0034)$. In conclusion, ALN treatment reversed the effects of ovariectomy on cancellous bone turnover and increased bone mass and bone strength in baboons. ( J. Clin. Invest. 1993. 92:2577-2586.) Key words: osteoporosis $\bullet$ alendronate $\bullet$ histomorphometry $\bullet$ bone strength $\bullet$ bone mineral density
\end{abstract}

\section{Introduction}

Osteoporosis is a reduction in bone mass associated with an increased risk of fractures (1-8). While the treatment of established osteoporosis is still controversial $(9,10)$, there is good

Some of these data were presented in abstract form at the annual meeting of the American Society for Bone and Mineral Research, Minneapolis, MN, Sept. 30 to Oct. 4, 1992.

Address correspondence to Dr. Gideon A, Rodan, Department of Bone Biology \& Osteoperosis Research, Merck Research Laboratories, West Point, PA 19486. 1993.

Received for publication 10 May 1993 and in revised form 6 July

1. Drs. Balena and Toolan should both be considered first authors of this study.

J. Clin. Invest.

(C) The American Society for Clinical Investigation, Inc. $0021-9738 / 93 / 12 / 2577 / 10 \$ 2.00$

Volume 92, December 1993, 2577-2586 indication that osteoporosis can be prevented (11-14). The increase in bone turnover, associated with loss of ovarian function, is quantitatively the most important contributing factor to bone loss in osteoporosis (15-20). A rational approach to prevention, other than estrogen replacement therapy, is therefore treatment that reduces bone resorption and bone turnover. Bisphosphonates are nonhydrolyzable, pyrophosphate analogues that bind to the hydroxyapatite in bone, by virtue of their bisphosphonate structure, and inhibit bone resorption (21). Aminobisphosphonates are among the most potent agents in this group (22). Alendronate sodium (ALN), ${ }^{2} 4-$ amino-1-hydroxybutylidene-1,1-bisphosphonic acid, trihydrate sodium salt, was shown to inhibit bone resorption in rats subjected to immobilization $(23,24)$ or estrogen deficiency (25) and in patients with Paget's disease (26) and postmenopausal osteoporosis (27).

The objective of this study was to evaluate the efficacy of the aminobisphosphonate ALN in preventing the bone loss caused by estrogen deficiency in a nonhuman primate model. Rats, dogs, sheep, pigs, and primates have been reported to lose bone after ovariectomy (28-36). We chose to study the ovariectomized baboon since baboons are relatively large primates, have menstrual cycles similar to humans, thus similar estrogen exposure, and exhibit intracortical Haversian remodeling. This enabled us to study the effects of ovariectomy and treatment at the tissue level in the context of bone changes similar to those produced by estrogen deficiency in humans. Animals were treated for 2 yr with two doses of ALN. Biochemical parameters of bone turnover, bone mineral density, and bone biopsies were evaluated at 3-, 6-, or 12-mo intervals. The effects of treatment up to $12 \mathrm{mo}$ in living baboons have been previously reported (37). At death, we carried out histomorphometric analysis of iliac crest as well as vertebrae and ex vivo measurements of bone strength in vertebrae and femora. The results obtained show that ALN treatment reverses the skeletal effects of ovariectomy and may be useful therapy for the prevention of postmenopausal bone loss.

\section{Methods}

28 adult female baboons (Papio anubis) weighing $\sim 14 \mathrm{~kg}$ were used in this study. Animals were fed standard laboratory food (Purina Monkey Chow) and fruit. All animals had a history of regular menstrual cycles. Each animal was evaluated by $\mathrm{x}$-rays to insure epiphyseal clo-

2. Abbreviations used in this paper: Ac.f, activation frequency; ALN, alendronate; AP, alkaline phosphatase; BFR/BS, bone formation rate per bone surface; BGP, osteocalcin; BMD, bone mineral density; LP, lysylpyridinoline; MAR, mineral apposition rate; MS/BS, mineralizing surface; OS/BS, osteoid surface; OVX, ovariectomy; Tb.Th., trabecular thickness; TRAP, tartrate-resistant acid phosphatase. 
sure, to confirm adult skeletal status, and to confirm the absence of skeletal abnormalities. Animals were assigned to one of four groups ( $n$ $=7 /$ group ) on the basis of body weight. Animals were housed and treated according to the U.S. Department of Agriculture guidelines for humane animal treatment.

Ovariectomy $(O V X)$. Three groups of baboons $(n=21)$ underwent surgery to remove the ovaries and uterus (OVX groups) as described in detail in Thompson et al. (37). All animals recovered from surgery without incident. The fourth group with intact ovaries was not exposed to surgery (non-OVX group).

Treatment with $A L N$. The ovariectomized baboons were treated with $0,0.05$, or $0.25 \mathrm{mg} \mathrm{ALN} / \mathrm{kg}$ i.v. every $2 \mathrm{wk}$. Under anesthesia, a catheter was inserted in the saphenous vein and $3 \mathrm{ml}$ of saline with or without ALN was infused over $3 \mathrm{~min}$. The baboons were killed after 2 yr of treatment. The weight of each animal was recorded. The effectiveness of ovariectomy was verified by inspection of the uterus for involutional atrophy. The spine and femora were harvested immediately and kept frozen at $-20^{\circ} \mathrm{C}$ for mechanical testing.

Serum and urine biochemistry. Blood samples were obtained at 3-mo intervals by vein puncture under anesthesia, 12-16 h after last feeding. Urine was collected from the bladder by sterile puncture. All samples were kept at $-70^{\circ} \mathrm{C}$ and were analyzed at the end of the study. Serum and urinary calcium $(\mathrm{mg} / \mathrm{dl})$ were measured by atomic-absorption spectroscopy. Serum tartrate-resistant acid phosphatase (TRAP $[\mathrm{U} / \mathrm{dl}])$, urinary and serum phosphate $(\mathrm{mg} / \mathrm{dl})$, and urinary creatinine $(\mathrm{mg} / \mathrm{dl})$ were measured with a Gemstar Analyzer (Electro-Nucleonics, Inc., Fairfield, NJ). Alkaline phosphatase (AP) was measured with a Kodak analyzer. Osteocalcin (BGP) ( $\mathrm{ng} / \mathrm{ml}$; Incstar, Stillwater, $\mathrm{MN})$, calcitonin, and intact parathyroid hormone $(\mathrm{pg} / \mathrm{ml}$; Nichols Institute, San Juan Capistrano, CA) were determined by RIA. Lysylpyridinoline (LP) was extracted from 1-ml urine samples by acid hydrolysis and subsequent low pressure CF-1 chromatography according to the method of Beardsworth et al. (38). LP was further resolved on HPLC according to the chromatographic method of Uebelhart et al. (39) and quantitated by comparison with an external standard (hydroxylysylpyridinoline). Final results were expressed as picomoles LP per micromole of creatinine.

Bone histomorphometry. All baboons were injected with calcein $(10 \mathrm{mg} / \mathrm{kg}$ i.v. $) 22$ and $8 \mathrm{~d}$ before death. At death the whole iliac crest was excised and fixed in $10 \%$ formalin. Wedge biopsies $1 \mathrm{~cm}$ in length were taken $\sim 2 \mathrm{~cm}$ below the postero-superior iliac spine. The first and fifth lumbar vertebrae were embedded in methylmethacrylate without prior decalcification (40). Sections of 6-10 $\mu \mathrm{m}$ thickness were cut with a Polycut S microtome (Reichert Jung, Heidelberg, Germany) and examined without further staining for dynamic histomorphometry or stained with toluidine blue and Masson's trichrome for static measurements. All morphometric measurements of bone remodeling were carried out in cancellous bone with semiautomatic image analysis system (System IV; Bioquant, Nashville, TN). Cancellous bone was demarcated from cortical bone following published criteria (41). Depending on the intercortical distances and the quality of the specimens, a cancellous tissue area of $11.68-41.04 \mathrm{~mm}^{2}$ was measured on each section of the iliac crest specimens and an area of $\sim 38 \mathrm{~mm}^{2}$ in the fifth lumbar vertebra. Cancellous bone volume was expressed as the amount of cancellous bone within the spongy space. Osteoid surface (OS/BS [\%]) was expressed as a percentage of bone surface and was measured only when it exceeded $2 \mu \mathrm{m}$ in thickness. Equidistant multiple measurements were taken for osteoid thickness (OTh. $[\mu \mathrm{m}]$ ). The mineralizing surface (MS / BS [\%]) was calculated as the sum of the length of the first label plus second label divided by two and expressed in percent of the bone surface. The mineral appositional rate $(\operatorname{MAR}[\mu \mathrm{m} / \mathrm{d}])$ was calculated as the mean distance between the first and second label at equidistant points divided by the labeling interval ( $14 \mathrm{~d}$ ). Bone formation rate was expressed per unit of bone surface (BFR/BS $\left[\mu \mathrm{m}^{3} / \mu \mathrm{m}^{2}\right.$ per yr]). Mineralization lag time (d) was calculated as O.Th/adjusted apposition rate. The activation frequency (Ac.F [per yr]) was calculated as BFR/BS per wall thickness. Indices of bone structure were calculated from area and perimeter measurements as described by Parfitt et al.
(42) and included trabecular thickness (Tb.Th. [ $\mu \mathrm{m}]$ ), trabecular number $($ per $\mathrm{mm})$ and trabecular separation $(\mu \mathrm{m})$. Histomorphometric data are reported in three-dimensional terms with the correction factor $(\times 0.78)$ for the obliquity of the section $(43)$.

Bone mineral density (BMD). BMD measurements were taken every $3 \mathrm{mo}$ on anesthetized animals. Single-photon absorptiometric measurements were taken on the radius one-third from the distal end using an SP2 scanner with an ${ }^{125}$ I source (Lunar Corp., Madison, WI). Dual-photon absorptiometric measurements of the lumbar spine (L1L4) and femoral neck were performed with a DP3 scanner with a ${ }^{153} \mathrm{Gd}$ source (Lunar Corp.). Details of the procedures are found in Thompson et al. (37). A reproducibility study was conducted to assess the effect of operator variability and radionuclide source strength on the bone mineral measurements. The results showed that the source age did not contribute to variation (coefficient of variation of $1-2 \%$ ) in bone mineral content values and substantial variation did not exist between operators ( coefficient of variation of 3-4\%).

Mechanical testing. Throughout preparation and testing, vertebrae and femora were wrapped in saline-soaked gauze and stored at $4^{\circ} \mathrm{C}$. All testing was performed on a servohydraulic materials testing machine (1331; Instron, Canton, MA) and the data were recorded and analyzed with Labtech Notebook software (Laboratory Technologies, Wilmington, MA) on a personal computer (316; Dell Computers, Austin, TX). All analyses were performed without prior knowledge of group assignments.

The length of one randomly selected femur from each animal was measured from the intercondylar notch to the piriformis fossae. The condyles were removed and the supracondylar and subtrochanteric regions of the diaphysis were embedded in square aluminum tubing with polymethylmethacrylate. These loading fixtures were placed 42.3 $\mathrm{mm}$ from the midpoint of the femur, and the femora were then tested to failure in three-point bending with the upper loading point aligned with the midpoint of the posterior surface. The load and displacement at failure were recorded and the bending stiffness was calculated from the linear portion of the load vs. displacement curve.

The femur distal to the subtrochanteric fixture was then removed and the neck was tested to failure in simulated single-legged stance. The load was applied to the femoral head, parallel to the axis of the diaphysis, through an aluminum cup lined with polymethylmethacrylate. The load and displacement at failure were recorded and the bending stiffness was calculated.

The contralateral femur provided transverse sections of cortical bone from the proximal diaphysis, cortical beams from the mid-diaphysis, and cylinders of trabecular bone from the femoral neck for testing. A transverse section, $1 \mathrm{~mm}$ in width, was taken from a standard location in each proximal femoral diaphysis with an Isomet low-speed diamond saw (Buehler, Lake Bluff, IL). The cross-sectional areas of both cortical bone and the medullary canal were measured and the maximum and minimum moments of inertia were determined from digitized images using the interactive computer software package (SLICE) and an image processing system (FD-5000; Gould, San Jose, CA). A cylinder of cortical bone was then obtained from a standard location along the central diaphysis. Cortical beams were cut from the anterior, posterior-medial, and lateral quadrants of the cylinder. The specimens were sanded manually to remove the periosteum and to create true beams $(2.2 \times 2.2 \times 22 \mathrm{~mm})$. These beams were then tested to failure in three-point bending. The load and displacement at failure were recorded and the bending stiffness was calculated. A diamond coring tool (3.4-mm internal diameter; Starlite, Rosemont, PA) was used to remove a cylinder of trabecular bone strength from a standard location within each femoral neck. The cylinders were cut to a length of $3.4 \mathrm{~mm}$ and were then compressed to failure. The elastic modulus and the strength were recorded. The cylinders were then defatted with a combination of ultrasonic bleaching and a water jet. The apparent density (hydrated weight divided by the volume of the intact specimen) and tissue density (hydrated weight divided by the hydrated weight minus the submerged weight) were determined by the method previously described by Carter and Hayes (44). 
The superior and inferior endplates of the $\mathrm{L} 3$ vertebrae were embedded in polymethylmethacrylate to create plano-parallel surfaces for testing. The vertebrae were then compressed to failure, the load and displacement at failure were recorded, and the bending stiffness was calculated. The vertebrae were then separated from the polymethylmethacrylate, and anteroposterior, lateral, and cephalocaudad radiographs were taken to identify any fractures through the endplates.

A cylinder of trabecular bone, $5.1 \mathrm{~mm}$ in diameter and oriented along the cephalocaudad axis, was removed from the geometric center of the L4 vertebrae. From each cylinder, two smaller cylinders, each 5.1 $\mathrm{mm}$ in length, were created. One cylinder contained dense trabecular bone inferior to the superior endplate, and the second contained less dense bone from the midbody. The cylinders were compressed to failure, and the elastic modulus and the strength were recorded. The cylinders were then defatted with a combination of ultrasonic bleaching and a water jet, and the apparent density, tissue density, and ash content were determined.

Statistical analysis. Means and standard deviation were computed for each variable for each time point of the study. One-way ANOVA was performed and significance was established at $P<0.05$. Intergroup comparisons were performed with the Fisher-protected least significant difference (PLSD) test. Differences between treatment group means greater than PLSD indicate significance. Linear regression analysis between biochemical markers and bone histology, and bone histology and bone density were done with Abacus Concepts Statview (Abacus Concepts Inc., Berkeley, CA).

Equality of group variances was tested with Levene's test. A oneway ANOVA was used with dose level as the grouping variable if the group variances were equal. If Levene's test indicated unequal variances, then Brown-Forsythe statistics were computed with the same grouping variable. If the grouping variable was shown to have a significant impact on the outcome variable of interest, then multiple comparison tests were performed with the Tukey method. Group differences were considered significant at $P<0.05$.

\section{Results}

Biochemical parameters. Measurements of biochemical markers of bone formation and resorption are shown in Fig. 1,
$A-D$. Serum AP (Fig. $1 A$ ), BGP (Fig. $1 B$ ), and TRAP (Fig. 1 $C$ ) were significantly elevated in OVX vehicle-treated animals, relative to non-OVX at 3 and $6 \mathrm{mo}$, and remained elevated throughout the study. ALN treatment maintained the value of these parameters at control non-OVX levels (lower dose) or below controls (higher dose, at some time points). The excretion of the bone collagen crosslink lysylpyridinoline/creatinine (Fig. $1 D$ ) was significantly elevated in the OVX vehicletreated animals, relative to non-OVX throughout the study, starting at $3 \mathrm{mo}$. At all time points ALN treatment reduced the excretion of lysylpyridinoline to non-OVX levels. There were no significant differences between the two doses of ALN, although the values were usually lower for the high dose. The suppression of bone resorption reached a steady state at 3 mo and did not increase with time during the $2 \mathrm{yr}$ of treatment. Both parameters of bone resorption declined after 9-12 mo in OVX-vehicle treated animals, suggesting a relative decrease in the overall bone resorption of the skeleton. The parameters of bone formation declined less (BGP) or not detectably (alkaline phosphatase), consistent with the longer duration of the formation phase in bone remodeling. Serum calcium, phosphate, parathyroid hormone calcitonin, and urinary calcium/creatine $(\mathrm{Ca} / \mathrm{Cr})$ and phosphate/creatinine $(\mathrm{Pi} / \mathrm{Cr})$ ratios at 2 yr postOVX showed no systematic changes as a function of treatment (Table I). The urinary $\mathrm{Ca} / \mathrm{Cr}$ and $\mathrm{Pi} / \mathrm{Cr}$ values varied widely among animals (the SD was $\sim 100 \%$ ) and no statistically significant differences among the groups were recorded.

Histomorphometry. Indices for iliac crest cancellous bone histomorphometry, after $2 \mathrm{yr}$ of treatment, are summarized in Table II. The bone volume was not statistically different between non-OVX, OVX vehicle, and OVX low-dose ALN animals, but it was significantly increased in animals receiving high-dose ALN. The activation frequency (Ac.f), which estimates the frequency of initiation of remodeling cycles on the bone surface, was increased twofold in OVX vehicle animals
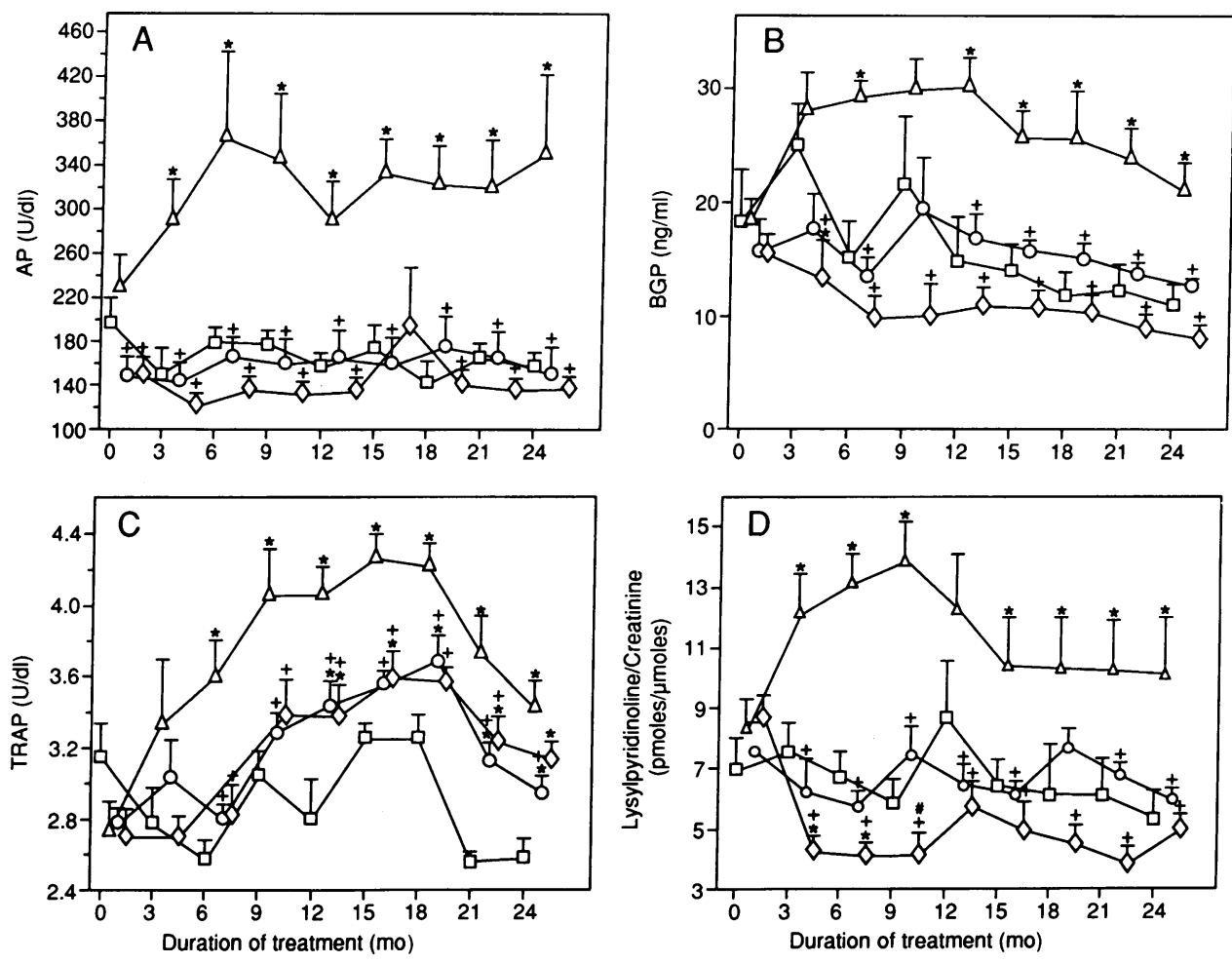

Figure 1. (A) Serum AP (U/dl). (B) Serum BGP $(\mathrm{ng} / \mathrm{ml})$. ( $C)$ Serum TRAP. (D) Urinary pyridinoline/creatinine excretion $(\mathrm{pmol} / \mu \mathrm{mol})$. Data are mean \pm SEM. ( $\square)$ Nonovariectomized animals (non-OVX), $(\Delta)$ ovariectomized vehicle-treated animals $(\mathrm{OVX}+\mathrm{VEH}),(\mathrm{O})$ ovariectomized animals treated with 0.05 $\mathrm{mg} / \mathrm{kg}$ ALN every 2 wk (OVX $+0.05 \mathrm{mg} / \mathrm{kg} \mathrm{ALN} \mathrm{i.v.)} \mathrm{and}(\diamond)$ ovariectomized animals treated with $0.25 \mathrm{mg} / \mathrm{kg}$ ALN every $2 \mathrm{wk}$ (OVX $+0.25 \mathrm{mg} / \mathrm{kg}$ i.v.). 


\begin{tabular}{|c|c|c|c|c|c|}
\hline & Non-OVX & OVX + VEH & $\begin{array}{l}\text { OVX + ALN } \\
(0.05 \mathrm{mg} / \mathrm{kg})\end{array}$ & $\begin{array}{l}\text { OVX + ALN } \\
(0.25 \mathrm{mg} / \mathrm{kg})\end{array}$ & ANOVA \\
\hline & & & & & $P$ \\
\hline \multicolumn{6}{|l|}{ Serum } \\
\hline iPTH (pg/ml) & $79.8 \pm 34.9$ & $49.1 \pm 24.5$ & $68.7 \pm 29.5$ & $74.5 \pm 25.2$ & NS \\
\hline \multicolumn{6}{|l|}{ Calcitonin } \\
\hline$(\mathrm{pg} / \mathrm{ml})$ & $11.7 \pm 6.99$ & $9.20 \pm 4.90$ & $6.51 \pm 3.28$ & $7.32 \pm 1.56$ & NS \\
\hline Calcium (mg/dl) & $8.27 \pm 0.61$ & $8.82 \pm 0.41^{*}$ & $8.85 \pm 0.49^{*}$ & $8.35 \pm 0.16$ & 0.04 \\
\hline \multicolumn{6}{|l|}{ Phosphate } \\
\hline$(\mathrm{mg} / \mathrm{dl})$ & $3.4 \pm 0.9$ & $4.3 \pm 1.5$ & $3.7 \pm 0.8$ & $4.1 \pm 0.9$ & NS \\
\hline \multicolumn{6}{|l|}{ Urine } \\
\hline $\mathrm{Ca} / \mathrm{Cr}$ & $0.11 \pm 0.03$ & $0.11 \pm 0.16$ & $0.07 \pm 0.06$ & $0.08 \pm 0.14$ & NS \\
\hline $\mathrm{Pi} / \mathrm{Cr}$ & $0.07 \pm 0.10$ & $0.09 \pm 0.17$ & $0.01 \pm 0.00$ & $0.04 \pm 0.04$ & NS \\
\hline
\end{tabular}

Data are mean \pm SD. * Significantly different from non-OVX controls; $P<0.05$.

and was decreased by ALN dose dependently. Similar changes were found in BFR/BS and OS/BS, which also reflect tissue level bone turnover. The mean values for osteoid thickness and mineral apposition rate were higher in the OVX vehicle animals, and no differences were observed between the ALNtreated and non-OVX animals. In none of the specimens was the mean osteoid thickness, corrected for section obliquity, $>12.5 \mu \mathrm{m}$. No significant changes were found in either the active formation period or in mineralization lag time between the various groups.

Table III presents indices of trabecular structure in the fifth lumbar vertebra. Bone volume was slightly reduced in the OVX vehicle as compared with non-OVX (not statistically significant). Treatment with ALN (both doses) resulted in significant bone gain. The increase in bone volume produced by ALN can be accounted for by a significant thickening of the trabeculae rather than by changes in trabecular number (density).
Table IV presents indices of bone remodeling in the lumbar vertebra. Consistent with the results observed in iliac crest, activation frequency and the various indices of bone turnover (OS/BS, MS/BS, BFR/BS BFR/BV) were still significantly elevated in the untreated animals $2 \mathrm{yr}$ after ovariectomy. These parameters were decreased by ALN treatment in a dose-dependent manner. Bone formation, expressed per unit of bone surface (BFR/BS) and as \%/yr (BFR/BV), was not significantly different between the higher and the lower ALN dose. No significant differences due to ovariectomy or treatment were observed in the number of multinucleated osteoclasts per unit bone surface, the extent of eroded surfaces, the osteoid thickness, or the mineral apposition rate.

Bone mineral density. Table $\mathrm{V}$ presents the bone density measurements. Radial BMD, which measures almost exclusively cortical bone, showed no statistically significant differences between the groups. Femoral neck BMD was significantly higher in animals treated with high-dose ALN as com-

Table II. Static and Dynamic Bone Histomorphometry in the Cranio-Caudal Iliac Crest

\begin{tabular}{|c|c|c|c|c|c|}
\hline & Non-OVX & OVX + VEH & $\begin{array}{l}\text { OVX + ALN } \\
(0.05 \mathrm{mg} / \mathrm{kg})\end{array}$ & $\begin{array}{l}\text { OVX + ALN } \\
(0.25 \mathrm{mg} / \mathrm{kg})\end{array}$ & ANOVA \\
\hline & & & & & $P$ \\
\hline $\mathrm{BV} / \mathrm{TV}(\%)$ & $28.8 \pm 7.02$ & $31.6 \pm 6.86$ & $35.0 \pm 5.37$ & $42.0 \pm 9.67^{*}$ & 0.0165 \\
\hline OS/BS (\%) & $15.3 \pm 9.11$ & $28.5 \pm 9.81^{\ddagger}$ & $10.1 \pm 1.47$ & $5.76 \pm 5.55^{\S}$ & 0.0001 \\
\hline OTh $(\mu \mathrm{m})$ & $9.46 \pm 1.87$ & $13.7 \pm 2.30^{\ddagger}$ & $9.23 \pm 1.00$ & $7.70 \pm 2.04$ & 0.001 \\
\hline $\operatorname{MAR}(\mu \mathrm{m} / \mathrm{d})$ & $0.63 \pm 0.11$ & $0.87 \pm 0.11^{\ddagger}$ & $0.63 \pm 0.09$ & $0.67 \pm 0.21$ & 0.0082 \\
\hline MS/BS (\%) & $16.40 \pm 10.53$ & $25.17 \pm 7.59^{\ddagger}$ & $14.2 \pm 3.73$ & $5.77 \pm 5.63$ & 0.0006 \\
\hline \multicolumn{6}{|l|}{ BFR/BS } \\
\hline$\left(\mu \mathrm{m}^{3} / \mu \mathrm{m}^{2}\right.$ per $\left.\mathrm{yr}\right)$ & $39.6 \pm 26.7$ & $81.4 \pm 31.9^{\ddagger}$ & $31.7 \pm 6.23$ & $14.3 \pm 12.7^{8}$ & 0.0001 \\
\hline Omt (d) & $15.1 \pm 1.48$ & $15.8 \pm 2.41$ & $15.2 \pm 3.32$ & $12.4 \pm 3.87$ & NS \\
\hline Mlt (d) & $18.2 \pm 12.6$ & $18.8 \pm 8.98$ & $10.9 \pm 1.36$ & $13.9 \pm 11.8$ & NS \\
\hline AcF (per yr) & $2.02 \pm 1.41$ & $4.85 \pm 1.55^{\ddagger}$ & $1.34 \pm 0.30$ & $0.62 \pm 0.52^{\S}$ & 0.0001 \\
\hline
\end{tabular}

Data are mean $\pm \mathrm{SD} ; n=7$ per group. ${ }^{*}$ Significantly different from non-OVX and OVX-VEH; $P<0.05 .{ }^{\ddagger}$ Significantly different from all other groups; $P<0.05$. 'Significantly different from non-OVX; $P<0.05$. 
Table III. Indices of Trabecular Architecture in the Fifth Lumbar Vertebra

\begin{tabular}{|c|c|c|c|c|c|}
\hline & Non-OVX & OVX + VEH* & $\begin{array}{l}\text { OVX + ALN } \\
(0.05 \mathrm{mg} / \mathrm{kg})\end{array}$ & $\begin{array}{l}\text { OVX + ALN } \\
(0.25 \mathrm{mg} / \mathrm{kg})\end{array}$ & ANOVA \\
\hline & & & & & $P$ \\
\hline BV/TV (\%) & $28.4 \pm 5.20$ & $23.1 \pm 4.18^{\ddagger}$ & $31.3 \pm 7.24$ & $33.8 \pm 8.25$ & 0.04 \\
\hline \multicolumn{6}{|l|}{$\mathrm{BS} / \mathrm{TV}$} \\
\hline$\left(\mathrm{mm}^{2} / \mathrm{mm}^{3}\right)$ & $3.61 \pm 0.57$ & $3.36 \pm 0.77$ & $3.56 \pm 0.95$ & $3.70 \pm 0.45$ & NS \\
\hline \multicolumn{6}{|l|}{ BS/BV } \\
\hline$\left(\mathrm{mm}^{2} / \mathrm{mm}^{3}\right)$ & $12.9 \pm 1.92$ & $14.6 \pm 3.00^{\ddagger}$ & $11.4 \pm 1.35$ & $11.5 \pm 2.82$ & 0.07 \\
\hline $\mathrm{Tb} \mathrm{Th}(\mu \mathrm{m})$ & $158.4 \pm 24.8$ & $141.1 \pm 26.2^{\ddagger}$ & $178.7 \pm 24.8$ & $182.9 \pm 45.6$ & 0.10 \\
\hline $\mathrm{Tb} \mathrm{N}($ per mm) & $1.80 \pm 0.28$ & $1.68 \pm 0.39$ & $1.78 \pm 0.48$ & $1.85 \pm 0.22$ & NS \\
\hline $\mathrm{Tb} \mathrm{Sp}(\mu \mathrm{m})$ & $407.2 \pm 82.6$ & $490.8 \pm 173.9$ & $438.9 \pm 246.4$ & $363.9 \pm 79.2$ & NS \\
\hline
\end{tabular}

Data are mean $\pm \mathrm{SD} ; n=7$ per group. ${ }^{*} n=6$. One baboon had monostotic dysplasia. ${ }^{*}$ Significantly different from OVX $+0.05 \mathrm{mg} / \mathrm{kg} \mathrm{ALN}$ and $\mathrm{OVX}+0.25 \mathrm{mg} / \mathrm{kg} \mathrm{ALN} ; P<0.05$.

pared with controls. BMD of the lumbar spine showed a significant reduction of $\sim 13 \%$ in the OVX vehicle group and a dose-dependent increase to non-OVX levels by ALN treatment. For the high dose, BMD was $15 \%$ higher than the OVX vehicle $(P<0.03)$.

The apparent density $\left(\mathrm{mg} / \mathrm{cm}^{3}\right)$ of $\mathrm{L} 4$ cancellous bone decreased by $17 \%$ in OVX vehicle relative to non-OVX. This reduction was fully prevented by low-dose ALN, and there was a $62 \%$ increase with high-dose ALN, relative to OVX vehicle.

A close correlation was observed between histomorphometric and biochemical parameters of bone turnover as well as BMD. The osteoid surface measured in the iliac crest showed a highly significant positive correlation $(r=+0.81, P<0.0001)$ with serum osteocalcin levels (Fig. $2 A$ ). The bone mineral density in the lumbar vertebrae (average of L2-L4) showed a statistically significant negative correlation with the bone turnover rate in the iliac crest (Fig. $2 \mathrm{~B}$ ), consistent with the notion that bone loss caused by estrogen deficiency is related to increased bone turnover.

Biomechanical measurements. The results of mechanical testing are summarized in Table VI. There were no differences among groups in mean body weights at death. The stiffness and failure load for the femoral midshaft and the neck did not differ among treatment groups. Neither the area measurements of the cortical bone and the medullary canal nor the inertial properties varied among groups. There were no differences among groups in stiffness or failure load of cortical beam specimens tested to failure in three-point bending. In addition, the modulus and strength of trabecular cylinders taken from the femoral neck did not vary significantly among groups. There were also no differences among groups in apparent density, tissue density, or ash content.

The data from six L3 vertebrae compressed to failure were excluded from analysis due to fracture through the endplates.

Table IV. Indices of Bone Remodeling in the Fifth Lumbar Vertebra

\begin{tabular}{|c|c|c|c|c|c|}
\hline & Non-OVX & OVX + VEH* & $\begin{array}{l}\text { OVX + ALN } \\
(0.05 \mathrm{mg} / \mathrm{kg})\end{array}$ & $\begin{array}{c}\text { OVX }+ \text { ALN } \\
(0.25 \mathrm{mg} / \mathrm{kg})\end{array}$ & ANOVA \\
\hline & & & & & $P$ \\
\hline OS/BS (\%) & $9.01 \pm 2.93$ & $13.51 \pm 7.96$ & $4.83 \pm 2.84^{\ddagger}$ & $2.24 \pm 3.28^{\S}$ & 0.0011 \\
\hline ES/Md BS (\%) & $2.37 \pm 1.17$ & $2.99 \pm 1.62$ & $3.36 \pm 0.73$ & $3.09 \pm 1.72$ & NS \\
\hline QS/BS (\%) & $88.85 \pm 3.50$ & $83.98 \pm 8.75$ & $91.98 \pm 2.87^{\ddagger}$ & $94.73 \pm 3.33^{\S}$ & 0.0054 \\
\hline OTh $(\mu \mathrm{m})$ & $5.68 \pm 1.10$ & $6.70 \pm 0.50$ & $6.51 \pm 1.34$ & $5.60 \pm 2.47$ & NS \\
\hline Omt (d) & $8.23 \pm 1.59$ & $7.50 \pm 1.57$ & $10.20 \pm 4.06$ & $10.0 \pm 2.78$ & NS \\
\hline OcN/Md BS (per mm) & $0.032 \pm 0.023$ & $0.049 \pm 0.037$ & $0.053 \pm 0.029$ & $0.031 \pm 0.023$ & NS \\
\hline OcS/Md.BS (\%) & $0.254 \pm 0.202$ & $0.156 \pm 0.105$ & $0.370 \pm 0.266$ & $0.151 \pm 0.106$ & NS \\
\hline $\operatorname{MAR}(\mu \mathrm{m} / \mathrm{d})$ & $0.70 \pm 0.13$ & $0.92 \pm 0.15$ & $0.71 \pm 0.22$ & $0.64 \pm 0.36$ & NS \\
\hline MS/BS (\%) & $5.13 \pm 2.97$ & $8.03 \pm 5.18$ & $3.98 \pm 2.41^{\ddagger}$ & $0.94 \pm 1.58^{\S}$ & 0.0056 \\
\hline \multicolumn{6}{|l|}{$\mathrm{BFR} / \mathrm{BS}$} \\
\hline$\left(\mu \mathrm{m} 3 / \mu \mathrm{m}^{2} /\right.$ per yr $)$ & $14.14 \pm 10.48$ & $28.26 \pm 21.78^{\prime \prime}$ & $10.95 \pm 7.02 \ddagger$ & $2.60 \pm 4.32^{\ddagger}$ & 0.0091 \\
\hline BFR/BV (\%/yr) & $12.54 \pm 8.37$ & $36.19 \pm 23.51^{11}$ & $9.71 \pm 9.88$ & $1.84 \pm 3.48$ & 0.0007 \\
\hline BFR/TV (\%/yr) & $3.45 \pm 2.30$ & $8.82 \pm 6.31^{11}$ & $3.19 \pm 3.11$ & $0.66 \pm 1.22$ & 0.0043 \\
\hline AcF (per yr) & $0.48 \pm 0.40$ & $0.86 \pm 0.67$ & $0.35 \pm 0.23^{\ddagger}$ & $0.086 \pm 0.14^{\ddagger}$ & 0.0153 \\
\hline
\end{tabular}

Data are mean \pm SD. ${ }^{*} n=6$. One baboon had monostotic dysplasia. ${ }^{\ddagger}$ Significantly different from OVX-VEH; $P<0.05$. Significantly different from non-OVX and OVX-VEH; $P<0.05$. 


\begin{tabular}{|c|c|c|c|c|c|}
\hline & Non-OVX & OVX + VEH & $\begin{array}{l}\text { OVX + ALN } \\
(0.05 \mathrm{mg} / \mathrm{kg})\end{array}$ & $\begin{array}{c}\mathrm{OV}+\mathrm{ALN} \\
(0.25 \mathrm{mg} / \mathrm{kg})\end{array}$ & ANOVA \\
\hline & & & & & $P$ \\
\hline $\mathrm{L} 1 \mathrm{BMD}\left(\mathrm{g} / \mathrm{cm}^{2}\right)$ & $1.17 \pm 0.19$ & $1.03 \pm 0.10^{*}$ & $1.11 \pm 0.04$ & $1.18 \pm 0.06$ & 0.06 \\
\hline L2 BMD (g/ $\left./ \mathrm{cm}^{2}\right)$ & $1.16 \pm 0.18$ & $1.01 \pm 0.06^{*}$ & $1.10 \pm 0.06$ & $1.18 \pm 0.08$ & 0.04 \\
\hline L3 BMD $\left(\mathrm{g} / \mathrm{cm}^{2}\right)$ & $1.13 \pm 0.13$ & $1.02 \pm 0.07^{*}$ & $1.08 \pm 0.06$ & $1.17 \pm 0.10$ & 0.03 \\
\hline L4 BMD $\left(\mathrm{g} / \mathrm{cm}^{2}\right)$ & $1.14 \pm 0.12$ & $1.01 \pm 0.08^{*}$ & $1.09 \pm 0.05$ & $1.14 \pm 0.12$ & 0.08 \\
\hline $\mathrm{L} 2-\mathrm{L} 4\left(\mathrm{~g} / \mathrm{cm}^{2}\right)$ & $1.14 \pm 0.14$ & $1.01 \pm 0.06^{\ddagger}$ & $1.09 \pm 0.05$ & $1.16 \pm 0.10^{\S}$ & 0.03 \\
\hline \multicolumn{6}{|l|}{ Femoral Neck BMD } \\
\hline $\left.\mathrm{g} / \mathrm{cm}^{2}\right)$ & $0.69 \pm 0.06$ & $0.73 \pm 0.04$ & $0.69 \pm 0.07$ & $0.77 \pm 0.05^{\prime \prime}$ & 0.04 \\
\hline $\begin{array}{c}\text { Radial BMD } \\
\left(\mathrm{g} / \mathrm{cm}^{2}\right)\end{array}$ & $0.49 \pm 0.05$ & $0.52 \pm 0.05$ & $0.52 \pm 0.04$ & $0.53 \pm 0.06$ & NS \\
\hline \multicolumn{6}{|l|}{ L4 Apparent } \\
\hline Density $\left(\mathrm{mg} / \mathrm{cm}^{3}\right)$ & $436.8 \pm 83.2$ & $365.2 \pm 57.1$ & $427.8 \pm 111.6$ & $592.1 \pm 204.4^{1}$ & 0.02 \\
\hline
\end{tabular}

Data are mean $\pm \mathrm{SD} ; n=7$ per group. * Significantly different from non-OVX and OVX $+0.25 \mathrm{mg} / \mathrm{kg} \mathrm{ALN} ; P<0.05$. ${ }^{\ddagger}$ Significantly different from non-OVX; $P<0.05$. ${ }^{8}$ Significantly different from OXV + VEH; $P<0.05$. "Significantly different from OVX and OVX $+0.05 \mathrm{mg} / \mathrm{kg}$ ALN; $P<0.05$. 'Significantly different from all other groups; $P<0.05$.

There were no differences among groups in stiffness, yield, or failure load.

The strength of the trabecular cylinders taken from the midbody of L4 varied among treatment groups. The strength of cylinders from the high-dose group was two times greater than the vehicle-treated group ( $16 \mathrm{vs.} 8 \mathrm{MPa}$ ). The strength of the cylinders taken inferior to the endplates also varied among groups. The strength of the high-dose group was two times greater than the vehicle-treated group and greater than the control group ( 18 vs. 9 and $11 \mathrm{MPa}$, respectively).

The apparent density of the trabecular cylinders taken from the midbody and endbody regions of L4 varied among treatment groups. The density of the endbody cylinders from animals given high-dose treatment was greater than those treated with vehicle $\left(0.592 \mathrm{vs} .0 .365 \mathrm{gm} / \mathrm{cm}^{3}\right)$. The density of the midbody cylinders from animals given high dose was greater than control and vehicle-treated groups $(0.400$ vs. 0.236 and 0.235 $\mathrm{gm} / \mathrm{cm}^{3}$, respectively). Tissue density did not vary among groups in either the midbody or endbody cylinders. Ash con- tent per dry weight of the midbody cylinders was not significantly different among groups. The cylinders from the endplate region did not differ in ash content among groups either.

Fig. $3 \mathrm{~A}$ depicts the correlation between in vivo measurements of BMD by dual-photon absorptiometry and ultimate strength of the L4 vertebral core. A highly significant positive correlation ( $r=0.94, P<0.003$ ) is present. Fig. $3 B$ shows the linear regression analysis between trabecular thickness (Tb.Th.) and the ultimate strength $(r=0.63, P<0.0005)$, which also shows a strong positive correlation.

\section{Discussion}

Although the molecular basis for estrogen deficiency-mediated bone loss is not fully understood, it is well established that estrogen deficiency after artificial $(16,45)$ or natural menopause $(18,46,47)$ causes an increase in bone turnover at the tissue and cellular level. Both bone resorption and bone forma-
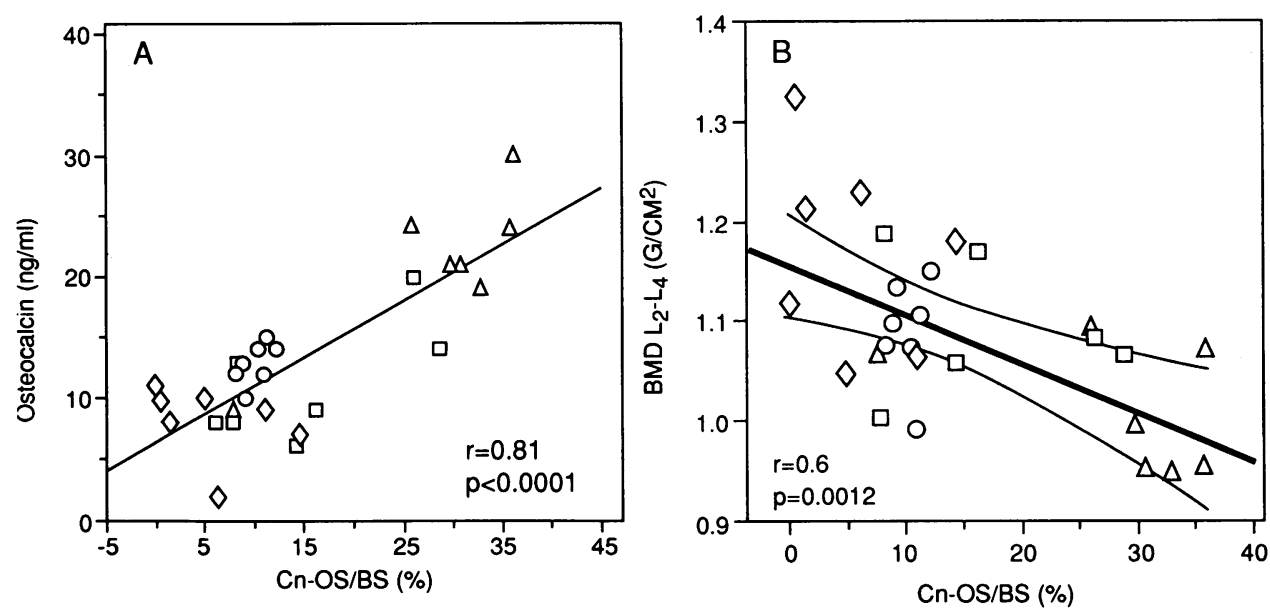

Figure 2. (A) Correlation of OS/BS $(\%)$, a measure of bone formation, and serum osteocalcin $(\mathrm{ng} / \mathrm{ml})$. Both parameters are measured as described in Methods on bone samples from the postero-superior iliac crest and sera obtained at 24 mo. Symbols are identified in Fig. 1. (B) Correlation of mean lumbar bone density ( $\mathrm{L} 2-\mathrm{L} 4\left[\mathrm{gm} / \mathrm{cm}^{2}\right]$ ) with cancellous osteoid surface/bone surface (Cn-OS/BS [\%]). BMD and $\mathrm{Cn}-\mathrm{OS} / \mathrm{BS}$ are measured as described in Methods on the vertebrae and on the superior-posterior iliac crest at $24 \mathrm{mo}$. Symbols are identified in Fig. 1. 


\begin{tabular}{|c|c|c|c|c|c|}
\hline & Non-OVX & OVX + VEH & $\begin{array}{l}\text { OVX + ALN } \\
(0.05 \mathrm{mg} / \mathrm{kg})\end{array}$ & $\begin{array}{l}\text { OVX }+ \text { ALN } \\
(0.25 \mathrm{mg} / \mathrm{kg})\end{array}$ & ANOVA \\
\hline & & & & & $P$ \\
\hline L4 strength & & & & & \\
\hline$(\mathrm{MPa})$ & $11.4 \pm 2.77$ & $9.24 \pm 1.36$ & $13.0 \pm 4.02$ & $18.3 \pm 6.96^{*}$ & 0.01 \\
\hline $\begin{array}{l}\text { Femoral midshaft } \\
\text { strength }(\mathrm{N})\end{array}$ & $2,391.6 \pm 219.9$ & $2,144.6 \pm 509.0$ & $2,352.2 \pm 303.7$ & $2,353.1 \pm 282.6$ & NS \\
\hline $\begin{array}{r}\text { Femoral neck } \\
\text { strength }(\mathrm{N})\end{array}$ & $135.6 \pm 35.9$ & $186.6 \pm 110.2$ & $173.4 \pm 78.0$ & $166.8 \pm 62.8$ & NS \\
\hline $\begin{array}{l}\text { Femoral stiffness } \\
\qquad(\mathrm{N} / \mathrm{mm})\end{array}$ & $1,531.7 \pm 150.2$ & $1,374.0 \pm 254.4$ & $1,429.5 \pm 185.7$ & $1,388.4 \pm 170.3$ & NS \\
\hline
\end{tabular}

Data are mean $\pm \mathrm{SD} ; n=7$ per group. ${ }^{*}$ Significantly different from all other groups; $P<0.05$.

tion rates are elevated, and the resulting bone loss indicates that resorption exceeds formation $(48,49)$. Estrogen replacement therapy decreases bone resorption and prevents bone loss ( 50 , 51 ), primarily by suppressing the rate of remodeling activation (52). In view of these findings, pharmacological agents that reduce bone resorption and thus bone turnover should have similar effects on the bone loss caused by estrogen deficiency (53-56). The aminobisphosphonate ALN is a potent inhibitor of bone resorption in vitro (57) and in vivo (23-27). This study examined its efficacy and mode of action in a model that resembles human estrogen deficiency bone loss.

ALN was administered intravenously to ensure full delivery, and the 2-wk interval between dosing was based on the estimated duration of the osteoclast resorption phase in the remodeling cycle. In hypercalcemia of malignancy, a single ad- ministration of bisphosphonate was shown to be effective for $\sim 2-3 \mathrm{wk}(58)$. The dose is based on previous experience in rats (23), which shows that $0.1 \mathrm{mg} / \mathrm{kg}$ given parenterally every $2 \mathrm{wk}$ is the maximally effective dose in most cases. This dose was bracketed in this study.

The bone changes in ovariectomized baboons were similar to those caused by estrogen deficiency in women. Biochemical markers of bone resorption, serum TRAP, and urinary lysylpyridinoline, a specific degradation product of bone collagen (59), had increased significantly 3 mo after ovariectomy and remained elevated throughout the study. Periodic measurements suggested that peak resorption was reached 9 mo after OVX. Parameters of bone formation showed similar increases: serum alkaline phosphatase was significantly elevated 3 mo after OVX, and continued to rise at $6 \mathrm{mo}$, when it leveled off at
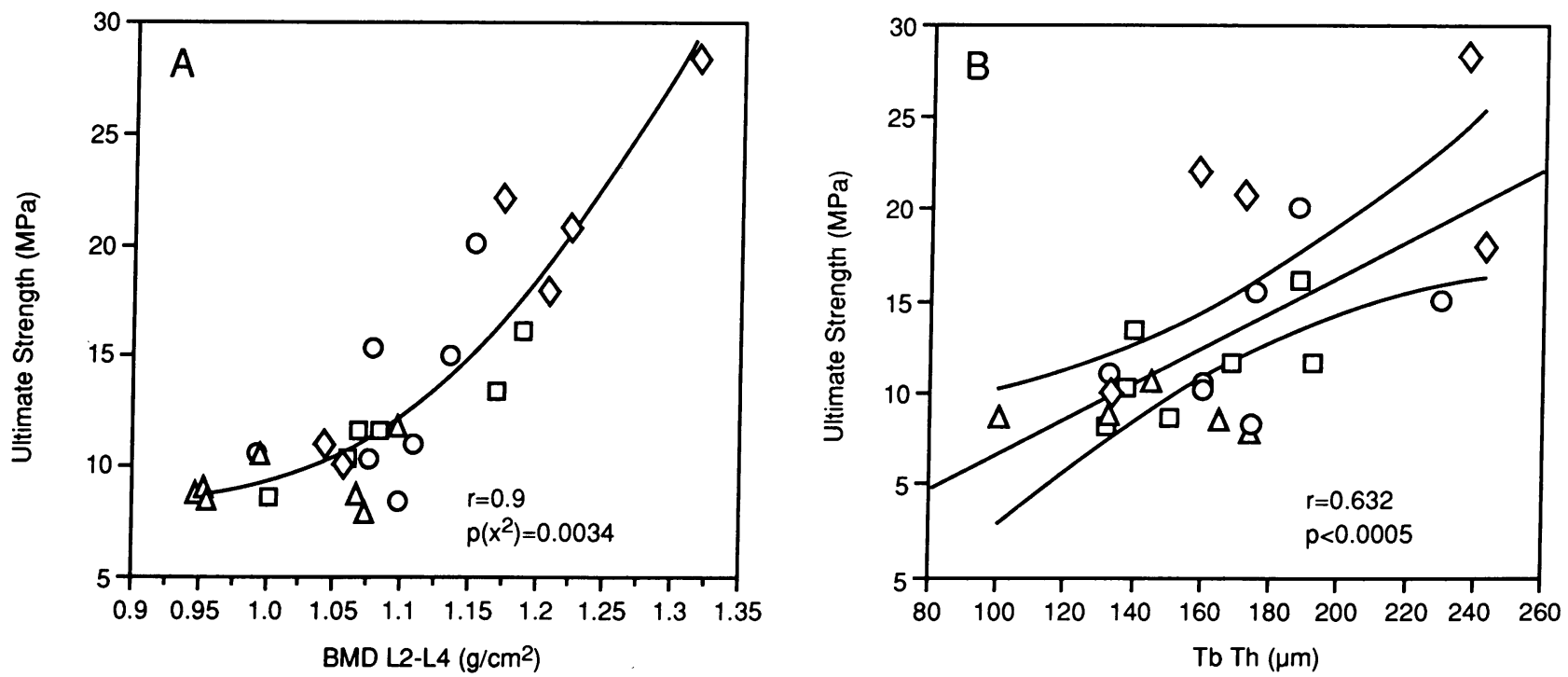

Figure 3. (A) Correlation of bone strength (MPa) estimated in the $\mathrm{L} 4$ vertebra and BMD ( $\mathrm{L} 2-\mathrm{L} 4\left[\mathrm{gm} / \mathrm{cm}^{2}\right]$ ). Ultimate strength is measured in the core of the L4 vertebra and BMD in the L2-L4 vertebrae at 24 mo as described in Methods. Symbols and animal groups are identified in Fig. 1. (B) Linear regression analysis between trabecular thickness ( Tb.Th. [ $\mu \mathrm{m}])$ measured in the fifth lumbar vertebra and ultimate vertebral bone strength $(\mathrm{MPa})$ measured in a core of cancellous core in the L4 vertebra. The findings suggest that ALN treatment suppressed bone turnover to control levels and produced no increasing effects over the $2 \mathrm{yr}$ of treatment, even at the higher ALN dose (corresponding to a 100-mg human oral dose, assuming $1 \%$ absorption). 
twofold the non-OVX level. Serum osteocalcin levels were twice as high 6 mo after OVX and remained $\sim 1.5-2$-fold higher than in non-OVX animals throughout the study, with an apparent decline between 12 and 24 mo in all groups. Each of the five biochemical parameters had sufficient sensitivity to detect increased bone turnover. As previously reported in postmenopausal women, both bone resorption and bone formation increase most during the initial period of estrogen deficiency (60). In this baboon population, the changes in bone metabolism after ovariectomy occur relatively fast and are more extensive than in postmenopausal women, where estrogen deficiency develops more gradually and occurs at a later biological age.

Analysis of iliac crest wedges at 24 mo showed that the parameters of bone turnover were still highly elevated in OVX vehicle-treated animals; the Ac.f was $4.9 / \mathrm{yr}$, compared with 2.0/yr in non-OVX; and the osteoid surface and bone formation rates were also approximately double those in non-OVX animals. ALN decreased bone turnover to non-OVX levels, the effects of the two doses were not significantly different.

Osteoid thickness and MAR increased in the OVX vehicle animals, which was probably a reflection of the large proportion of newly formed remodeling sites (61). ALN had no deleterious effect on mineralization, as both MAR and osteoid thickness were maintained at non-OVX levels. In contrast to the 1 -yr biopsies (37), the cancellous bone volume in the iliac crest was not significantly different between OVX vehicle and nonOVX. This could be explained by variations in the sampling site of the iliac biopsies, shown to be associated with differences in bone volume in humans (62). Although the bone formation rate at the tissue level (BFR/BS) was significantly increased in untreated OVX animals, the amount of bone formed (mean wall thickness) at the bone multicellular unit (BMU) level was decreased, both in the iliac crest and in the fifth lumbar vertebra (data not shown). These observations suggest that a decrease in the amount of bone made per each remodeling cycle is part of the mechanism of bone loss.

To study the mode of action of ALN at the tissue level in vertebral bone, which cannot be assessed in clinical studies, we also analyzed the L5 vertebra histomorphometrically. Cancellous bone volume was $\sim 23 \%$ lower in OVX vehicle-treated animals than in non-OVX, but the difference was not statistically significant. ALN treatment, at both doses, increased bone volume above that in non-OVX animals, consistent with the bone mineral density measurements before death.

The increase in cancellous bone volume with ALN treatment was due to an increase in trabecular thickness without changes in trabecular connectivity and correlated with increased strength (see below). These findings are consistent with those of Grynpas et al. (63), who reported an increase in Tb.Th. and bone strength without changes in connectivity, after administration of pamidronate in dogs. In agreement with the findings of Meunier and Coupron (64), we found that cancellous bone in the vertebra was significantly lower than in the iliac crest.

As seen in the iliac crest, ALN treatment reduced bone turnover in L5 to control (non-OVX) levels and, even at a multiple of the pharmacological dose, ALN did not abolish bone turnover. As opposed to the iliac crest, MAR and osteoid thickness in L5 were not increased in OVX vehicle baboons. This is consistent with the relatively lower rate of turnover observed in the vertebra, which was about half that recorded in the iliac crest. This is also consistent with region-specific differences in bone formation rates reported in human subjects (65) and the estimation by Parfitt (66) that the rate of turnover of cancellous bone in the ilium is $\sim 40 \%$ per year, compared with $\sim 20 \%$ in the vertebrae.

An interesting observation bearing on the mode of action of ALN and probably other aminobisphosphonates is the fact that the number of osteoclasts, as well as the extent of the osteoclast bone interface, were not different among the various groups, suggesting that ALN inhibition of bone resorption is not due to a reduction in osteoclast number (recruitment) or their attraction to the bone surface. Rather, ALN appears to inhibit osteoclast activity after their interaction with ALN-covered resorption surfaces (67). These findings are consistent with other similar observations in vivo and in vitro $(23,57,68)$.

The initial changes in BMD, after ovariectomy in baboons, are consistent with similar observations in estrogen-deficient women. BMD in L4 was significantly lower 6 mo after ovariectomy in the OVX untreated vs. non-OVX controls (37) and at $2 \mathrm{yr}$ the difference was $\sim 10 \%$. This is in agreement with the findings by Mazess et al. (34), who reported an $\sim 8 \%$ reduction in Macaca lumbar BMD 22 mo after OVX. During the 2 yr of study, the lumbar BMD in the non-OVX animals had increased by $9 \%$. In the OVX vehicle group, BMD also increased after $6 \mathrm{mo}$, when it reached the nadir, and had returned to about initial levels after $2 \mathrm{yr}$. This could reflect periosteal bone growth. In animals treated with high-dose ALN, BMD was maintained throughout the study at non-OVX levels, while the low-dose ALN had intermediate values between OVX vehicle and non-OVX.

To examine the "quality" of the bone accreted as a result of ALN treatment, L4 vertebrae and femora, excised at death, were subjected to ex vivo mechanical testing. Neither ovariectomy nor ALN treatment produced changes in the femora or femoral neck, consistent with the lower turnover of cortical bone, also indicating that ALN present in the bone after $2 \mathrm{yr}$ of treatment had no deleterious effects on the mechanical properties of cortical bone. Similar findings were obtained after 3 yr of ALN treatment in dogs (69).

The strength of a core of cancellous bone from the L4 vertebra in a compression test increased significantly after $2 \mathrm{yr}$ of treatment with ALN, relative to the OVX vehicle group. A correlation analysis of vertebral strength and bone mineral density (Fig. $3 A$ ) showed that strength increased with the square of the density, similar to the relationship found in human vertebrae obtained from cadavers (70). These findings demonstrate that the accretion of bone produced by ALN treatment contributed to bone strength, as does normal bone, consistent with the extensive epidemiological evidence showing that fracture incidence is inversely related to BMD (1-8).

In conclusion, this study shows that: (a) similar to women, baboons experience increased bone turnover and bone loss after ovariectomy, and $(b)$ continuous ALN treatment for $2 \mathrm{yr}$ normalized bone turnover, prevented the bone loss, and increased vertebral bone strength to control levels.

\section{Acknowledgments}

We thank John Davidson and Dana Burkholder for the densitometry measurements, Ms. Dianne McDonald for preparation of the manuscript, and Mr. Jeff Campbell for the art work. 


\section{References}

1. Nordin, B. E. C., B. E. Chatterton, C. J. Walker, and J. Wishart. 1987. The relation of forearm mineral density to peripheral fractures in postmenopausal women. Med. J. Aust. 146:300-304.

2. Isnich, R. D., P. D. Ross, J. W. Davis, and J. M. Vogel. 1989. A comparison of single and multi-site BMC measurements for assessment of spine fracture probability. J. Nucl. Med. 30:1166-1171.

3. Hui, S. L., C. W. Slemenda, and C. C. Johnston. 1989. Baseline measurement of bone mass predicts fracture in white women. Ann. Intern. Med. 111:355361.

4. Cummings, S. R., D. M. Black, M. C. Nevitt, W. S. Browner, J. A. Cauley, H. K. Genant, S. R. Mascioli, J. C. Scott, D. G. Seeley, P. Steiger, and T. M. Vogt. 1990. Appendicular bone density and age predict hip fracture in women. J. Am. Med. Assoc. 263:665-668.

5. Cleghorn, D. B., K. J. Polley, M. J. Bellon, J. Chatterton, P. A. Baghurst, and B. E. C. Nordin. 1991. Fracture rates as a function of forearm mineral density in normal postmenopausal women: retrospective and prospective data. Calcif Tissue Int. 49:161-163.

6. Chevalley, T., R. Rizzoli, V. Nydegger, D. Slosman, L. Tkatch, C.-H. Rapin, H. Vasey, and J.-P. Bonjour. 1991. Preferential low bone mineral density of the femoral neck in patients with a recent fracture of the proximal femur. Osteoporosis Int. 1:147-154.

7. Gardsell, P., O. Johnell, and B. E. Nilsson. 1991. The predictive value of bone loss for fragility fractures in women: a longitudinal study over 15 years. Calcif. Tissue Int. 49:90-94.

8. Duboeuf, F., P. Braillon, M. C. Chapuy, P. Haond, C. Hardouin, M. F. Meary, P. D. Delmas, and P. J. Meunier. 1991. Bone mineral density of the hip measured with dual-energy $\mathrm{x}$-ray absorptiometry in normal elderly women and in patients with hip fracture. Osteoporosis Int. 1:242-249.

9. Marcus, R. 1991. Understanding Osteoporosis. West. J. Med. 155:1.

10. Parfitt, A. M. 1992. Implications of architecture for the pathogenesis and prevention of vertebral fracture. Bone (Elmsford.). 13:S41-S47.

11. Reginster, J. Y., M. P. Lecart, R. Deroisy, N. Sarlet, D. Denis, J. Collette and P. Franchimont. 1989. Prevention of postmenopausal bone loss by tiludronate. Lancet. ii:1469-1471.

12. Valkema, R., F.-J. F. E. Vismans, S. E. Papapoulos, E. K. J. Powels, and O. L. M. Bijvoet. 1989. Maintained improvement in calcium balance and bone mineral content in patients with osteoporosis treated with the bisphosphonate APD. Bone Miner. 5:183-192.

13. Ettinger, B. 1988. Prevention of Osteoporosis: treatment of Estradiol Deficiency. Obstet. Gynecol. 72:125-175.

14. Lindsay, R. 1988. Prevention and treatment of osteoporosis with ovarian hormones. Ann. Chir. Gynaecol. 77:219-223.

15. Delmas, P. D. 1992. Clinical use of biochemical markers of bone remodeling in osteoporosis. Bone (Elmsford). 13(Suppl. 1):S17-S21.

16. Reeve, J. 1987. Bone turnover and trabecular plate survival after artificial menopause. Br. Med. J. Clin. Res. 295(6601):757-760.

17. Delmas, P. D., A. Schlemmer, E. Gineyts, B. Riis, and C. J. Christiansen, 1991. Urinary excretion of pyridinoline crosslinks correlates with bone turnover measured on iliac crest biopsy in patients with vertebral osteoporosis. J. Bone Miner. Res. 6:639-644.

18. Uebelhart, D., A. Schlemmer, J. S. Johansen, E. Bineyts, C. Christiansen, and P. D. Delmas. 1991. Effect of menopause and hormone replacement therapy on the urinary excretion of pyridinium cross-links. J. Clin. Endocrinol. \& Metab. 72:367-373.

19. Stepan, J. J., J. Pospichal, J. Presl, and V. Pacovsky. 1987. Bone loss and biochemical indices of bone remodeling in surgically induced postmenopausal women. Bone (Elmsford). 8:279-284.

20. Frost, H. M. 1985. The pathomechanics of osteoporosis. Clin. Orthop Relat. Res. 200:198-225.

21. Fleisch, H. 1987. Bisphosphonates: history and experimental basis. Bone (Elmsford). 8(Suppl.):523-528.

22. Schenk, R., P. Eggli, H. Fleisch, and S. Rosini. 1986. Quantitative morphometric evaluation of the inhibitory activity of new aminobisphosphonates on bone resorption in the rat. Calcif. Tissue Int. 38:342-349.

23. Thompson, D. D., J. G. Seedor, M. Weinreb, S. Rosini, and G. A. Rodan 1990. Aminohydroxybutane bisphosphonate inhibits bone loss due to immobilization in rats. J. Bone Miner. Res. 5:279-286.

24. Weinreb, M., G. A. Rodan, and D. D. Thompson. 1989. Osteopenia in the immobilized rat limb is associated with increased bone resorption and decreased bone formation. Bone (Elmsford). 10:187-194.

25. Seedor, J. G., H. A. Quartuccio, and D. D. Thompson. 1991. The bisphosphonate alendronate (ALN) inhibits bone loss due to ovariectomy in rats. $J$ Bone Miner. Res. 6:339-346.

26. O’Doherty, D. P., D. R. Bickerstaff, E. V. McCloskey, N. A. T. Hamdy, M. N. C. Beneton, S. Harris, M. Mian, and J. A. Kanis. 1990. Treatment of
Paget's disease of bone with amino-hydroxybutylidene bisphosphonate. J. Bone Miner. Res. 5:483-491.

27. Passeri, M., M. C. Baroni, M. Pedrazzoni, G. Pioli, M. Barbagallo, D. Costi, M. Biondi, G. Girasole, B. Arlunno, and E. Palummeri. 1991. Intermittent treatment with intravenous 4-amino-1-hydroxybutylidene-1,1-bisphosphonate (AHBUBP) in the therapy of postmenopausal osteoporosis. Bone Miner. 15:237247.

28. Turner, R. T., J. J. Vandersteenhoven, and N. H. Bell. 1987. The effects of ovariectomy and $17 \beta$-estradiol on cortical bone histomorphometry in growing rats. J. Bone Miner. Res. 2:115-122.

29. Wronski, T. J., M. Cintron, and L. M. Cann. 1989. Temporal relationship between bone loss and increased bone turnover in ovariectomized rats. Calcif. Tissue Int. 43:179-183.

30. Dannucci, G. A., R. B. Martin, and P. Patterson-Buckendahl. 1987. Ovariectomy and trabecular bone remodeling in the dog. Calcif. Tissue Int. 40:624630.

31. Boyce, R. W., A. F. Franks, M. L. Jankowski, C. M. Orcutt, A. M. Piacquadio, J. M. White, and J. A. Bevan. 1990. Sequential histomorphometric changes in cancellous bone from ovariohysterectomized dogs. J. Bone Miner. Res. 5:947-953.

32. Mosekilde, L., S. E. Weisbrode, J. A. Safron, H. G. Stills, M. L. Jankowsky, D. C. Ebert, C. C. Danielsen, C. H. Sgaard, A. F. Franks, M. L. Stevens, C. L. Paddock, and R. Boyce. 1992. Calcium-restricted ovariectomized Sinclair S-1 minipig. An animal model of osteopenia and trabecular plate perforation. Bone (Elmsford). 13:A24.

33. Pastoureau, P., M. E. Arlot, F. Caulin, J. P. Barlet, P. J. Meunier, and P. D. Delmas. 1989. Effects of oophorectomy on biochemical and histological indices of bone turnover in ewes. J. Bone Miner. Res. 4(Suppl. 1):S237.

34. Mazess, B., J. Vetter, and D. S. Weaver. 1987. Bone changes in oophorectomized monkeys: CT findings. J. Comput. Assisted Tomogr. 11(2):302-305.

35. Longscope, C., L. Hoberg, S. Sleuterman, and D. Barin. 1989. The effect of ovariectomy on spine bone mineral density in Rhesus monkeys. Bone (Elms ford). 10:341-344.

36. Jerome, C. P., D. B. Kimmel, J. A. McAlister, and D. S. Weaver. 1986. Effects of ovariectomy on iliac trabecular bone in baboons (Papio anubis). Calcif. Tissue Int. 39:206-208.

37. Thompson, D. D., J. G. Seedor, H. Quartuccio, H. Solomon, C. Fioravanti, J. Davidson, H. Klein, R. Jackson, J. Clair, D. Frankenfield, E. Brown, H. A. Simmons, and G. A. Rodan. 1992. The bisphosphonate, alendronate, prevents bone loss in ovariectomized baboons. J. Bone Miner. Res. 7:951-960.

38. Beardsworth, L. J., D. R. Eyre, and I. R. Dickson. 1990. Changes with age in the urinary excretion of lysyl- and hydroxylysylpyridinoline, two new markers of bone collagen turnover. J. Bone Miner. Res. 5:671-676.

39. Uebelhart, D., E. Gineyts, M.-C. Chapuy, and P. D. Delmas. 1990. Urinary excretion of pyridinium crosslinks: a new marker of bone resorption in metabolic bone disease. Bone Miner. 8:87-962.

40. Baron, R., A. Vignery, L. Neff, A. Silverglate, and A. Santa Maria. 1983. Processing of undecalcified bone specimens for bone histomorphometry. In Bone Histomorphometry: Techniques and Interpretation. R. Recker, editor. CRC Press, Inc., Boca Raton, FL. 13-35.

41. Duncan, H. 1973. Cortical porosis: a morphological evaluation. In Bone Morphometry Proceedings of the First Workshop on Bone Morphometry.

Z. F. G. Jaworski, editor. University of Ottawa Press, Ottawa, Canada. 78-83.

42. Parfitt, A. M., C. H. E. Mattews, A. R. Villanueva, M. Kleerekoper, B. Frame, and D. S. Rao. 1983. Relationships between surface, volume, and thickness of iliac trabecular bone in aging and in osteoporosis. Implications for the micro anatomic and cellular mechanisms of bone loss. J. Clin. Invest. 72:13961409.

43. Parfitt, A. M., M. K. Drezner, F. H. Glorieus, J. A. Kanis, H. Malluche, P. J. Meunier, S. M. Ott, and R. R. Recker. 1987. Bone histomorphometry nomenclature, symbols and units. Report of the ASBMR histomorphometry committee. J. Bone Miner. Res. 2:595-610.

44. Carter, D. R., and W. C. Hayes. 1977. The compressive behavior of bone as a two-phase porous structure. J. Bone Jt. Surg. Am. Vol. 59A:954.

45. Stepan, J. J., J. Pospichal, V. Schreiber, J. Kanka, J. Mensik, J. Presl, and V. Pacovsky. 1989. The application of plasma tartrate-resistant acid phosphatase to assess changes in bone resorption in response to artificial menopause and its treatment with estrogen or norethisterone. Calcif. Tissue Int. 45:273-280.

46. Kelly, P. J., N. A. Pocock, P. N. Sambrook, and J. A. Eisman. 1989. Age and menopause-related changes in indices of bone turnover. Endocrinol. Metab. Clin. North Am. 69:1160-1165.

47. Smith, M. L., I. Fogelman, D. M. Hart, E. Scott, J. Bevan, and I. Leggate. 1989. Effect of etidronate disodium on bone turnover following surgical menopause. Calcif. Tissue Int. 44:74-79.

48. Genant, H. K., C. E. Cann, B. Ettinger, and G. S. Gordan. 1982. Quantitative computed tomography of vertebral spongiosa: a sensitive method for detecting early bone loss after oophorectomy. Ann. Intern. Med. 97:699-705.

49. Hreshchyshyn, M. M., A. Hopkins, S. Zylstra, and M. Anbar. 1988. Ef- 
fects of natural menopause, hysterectomy, and oophorectomy on lumbar spine and femoral neck bone densities. Obstet. Gynecol. 73:631-638.

50. Lindsay, R., D. M. Hart, C. Forrest, and C. Baird. 1980. Prevention of spinal osteoporosis in oophorectomized women. Lancet ii:1151-1154.

51. Civitelli, R., D. Agnusdei, P. Nardi, F. Zacchei, L. V. Avioli, and C. Gennari. 1988. Effects of one-year treatment with estrogens on bone mass, intestinal calcium absorption, and 25-hydroxyvitamin D-1 $\alpha$-hydroxylase reserve in postmenopausal osteoporosis. Calcif. Tissue Int. 42:77-86.

52. Steiniche, T., C. Hasling, P. Charles, E. F. Eriksen, L. Mosekilde, and F. Sheffield. 1989. Effects of estrogen gestagen or high dose oral calcium on trabecular bone remodeling in postmenopausal osteoporosis. Bone (Elmsford). 10:313320.

53. Parfitt, A. M. 1991. Use of bisphosphonates in the prevention of bone loss and fractures. Am. J. Med. 915B:S-42-46.

54. Watts, N. B., S. T. Harris, H. K. Genant, R. D. Wasnich, P. D. Miller, R. D. Jackson, A. A. Licata, P. Ross, G. C. Woodson, M. J. Yanover, W. J. Mysiw, L. Kohse, M. B. Rao, P. Steiger, B. Richmond, and C. H. Chestnut. 1990 Intermittent cyclical etidronate treatment of postmenopausal osteoporosis. $N$. Engl. J. Med. 323:73-79.

55. McCloskey, E. V., M. N. C. Beneton, M. O'Rourke, K. Eyres, D. O'Doherty and J. A. Kanis. 1990. The effect of phosphate and intermittent clodronate in postmenopausal osteoporosis. In Osteoporosis. C. Christiansen and K. Overgaard, editors. Osteopress ApS, Copenhagen. 1401-1402.

56. Mazzouli, G. F., S. Tabolli, F. Bigi, C. Valtorta, S. Minisola, D. Diacinti, L. Scarnecchia, G. Bianchi, M. Piolini, and S. Dell'Acqua. 1990. Effects of salmon calcitonin on the bone loss induced by ovariectomy. Calcif. Tissue Int. 47:209-214.

57. Sato, M., and W. Grasser. 1990. Effects of bisphosphonates on isolated rat osteoclast as examined by reflected light microscopy. J. Bone Miner. Res. 5:3140.

58. Zysset, E., P. Ammann, A. Jenzer, B. J. Gertz, L. Portmann, R. Rizzoli, F. Jaquet-Muller, S. Pryor-Tillotson, J.-P. Bonjour, and P. Burckhardt. 1992. Comparison of a rapid (2-h) versus a slow (24-h) infusion of alendronate in the treatment of hypercalcemia of malignancy. Bone Miner. 18:237-249.

59. Delmas, P. D. 1990. Biochemical markers of bone turnover for the clinical assessment of metabolic bone disease. Endocrinol. Metab. Clin. North Am. 19:118.
60. Ohta, H., K. Makita, Y. Suda, T. Ikeda, T. Masuzawa, and S. Nozawa. 1992. Influence of oophorectomy in serum levels of sex steroids and bone metabolism and assessment of bone mineral density in lumbar trabecular bone by QCTC value. J. Bone Miner. Res. 7:659-665.

61. Parfitt, A. M. 1990. Bone forming cells in clinical conditions. In Bone, A Treatise, Vol. 1: The Osteoblast and Osteocyte. B. K. Hall, editor. The Telford Press, Caldwell, NJ. 351-429.

62. Moore, R. J. T. C. Durbridge, A. E. Woods, and B. Vernon-Roberts. 1989. Variation in histomorphometric estimates across different sites of the iliac crest. J. Clin. Pathol. 42:814-816.

63. Grynpas, M. D., A. Acito, M. Dimitriu, B. P. Mertz, and J. M. Very. 1992 Changes in bone mineralization, architecture and mechanical properties due to long-term ( 1 year) administration of pamidronate (APD) to adult dogs. Osteoporosis Int. 2:74-81.

64. Meunier, P. J., and P. Coupron. 1976. Iliac trabecular bone volume in 236 controls representativeness of iliac samples. In Proceedings of the First Workshop on Bone Morphometry. Z. F. G. Jaworski, editor. University of Ottawa Press, Ottawa, Canada. 100-105

65. Mellish, R. W. E., M. W. Ferguson-Pell, G. V. B. Cochran, R. Lindsay, and D. W. Dempster. 1991. A new manual method for assessing two-dimensional cancellous bone structure: comparison between iliac crest and lumbar vertebra. $J$. Bone Miner. Res. 6:689-696.

66. Parfitt, A. M. 1983. The physiological and clinical significance of bone histomorphometric data. In Bone Morphometry. Techniques and Interpretations. R. Recker, editor. CRC Press, Inc., Boca Raton, FL. 143-223.

67. Sato, M., W. Grasser, N. Endo, R. Akins, H. Simmons, D. D. Thompson, E. Golub, and G. A. Rodan. Bisphosphonate action: alendronate localization in rat bone and effects on osteoclast ultrastructure. J. Clin. Invest. 88:2095-2105.

68. Storm, T., T. Steiniche, G. Thamsborg, and F. Melsen. 1993. Changes in bone histomorphometry after long term treatment with intermittent, cyclic etidronate for post-menopausal osteoporosis. J. Bone Miner. Res. 8:199-208.

69. Balena, R., A. Markato, J. Guy, M. Shea, J. G. Seedor, W. C. Hayes, C. P. Peter, and G. A. Rodan. 1993. Effects of three years treatment with alendronate in adult beagles. J. Bone Miner. Res. 8:S270.

70. Jensen, K. S., L. Mosekilde, and L. Mosekilde. 1990. A model of vertebral trabecular bone architecture and its mechanical properties. Bone (Elmsford.) 11:417-423. 